\title{
Optical Properties of Natural and Synthetic Minerals
}

\author{
Vera Skvortsova, Nina Mironova - Ulmane, Laima Trinkler \\ Institute of Solid State Physics University of Latvia. Address: 8 Kengaraga St., LV-1063, \\ Riga, Latvia
}

\begin{abstract}
The results of investigation of optical absorption and photoluminescence (PL) of topaz, beryl and yttrium aluminium garnet crystals doped with different concentrations of transition ions exposed to fast neutron irradiation and electron irradiation are presented. We suppose that irradiation leads to the formation of two types of complex centers: " $\mathrm{Me}^{2+}-\mathrm{F}^{+}$(or $\left.\mathrm{F}\right)$ centre" and complex centers, which consist of a cation vacancy and an impurity (iron, manganese and chromium) ion. Exchange interaction between radiation defects and impurity ions during neutron or electron irradiation gives rise to appearance of additional absorption and luminescence band broadening in investigated crystals.
\end{abstract}

Keywords - inorganic compounds, absorption spectra, photoluminescence, neutron irradiation.

\section{INTRODUCTION}

Natural and synthetic minerals such as topaz, beryl and garnet are used not only as gemstone but have a practical application. Topaz crystal is a suitable material for dosimetric applications [1]-[3]. Beryl and garnet crystals doped with transition metal ions find application as laser materials [4], [5]. Most gemstone crystals have an intrinsic color due to the optical absorption and presence of color centers that are produced by impurities like transition metals and elements of Earth-rare, or defects in the crystalline lattice [6]. Defect and disorder creation has been studied in detail, but the renewed interest arises from the use of electron and ion beams for synthesis and modification of materials.

Potential application of this material to a great extent is determined by its optical properties, which in turn are determined not only be structure but also by presence of defects. Therefore it is important to estimate the present material defects and their effect on properties of material.

The paper presents results of the effects of neutron and electron irradiation on optical properties of natural (topaz, beryl) and synthetic (beryl, yttrium aluminum garnet) minerals.

\section{MATERIALS AND METHODS}

Oxide materials $\mathrm{Y}_{3} \mathrm{Al}_{5} \mathrm{O}_{12}$, natural and synthetic beryl $\mathrm{Be}_{3} \mathrm{Al}_{2} \mathrm{Si}_{6} \mathrm{O}_{18}$, topaz $\mathrm{Al}_{2}\left[\mathrm{SiO}_{4}\right](\mathrm{F}, \mathrm{OH})_{2}$ have been used for research.

The investigated YAG samples were cut from single crystals grown by the Czochralski technique, crystal had the composition. $\mathrm{Y}_{3} \mathrm{Al}_{5-\mathrm{x}} \mathrm{Mn}_{. \mathrm{x}} \mathrm{O}_{12}$, where $\mathrm{x}$ $=0.012,0.025,0,037$ and 0.05 . Samples of beryl were obtained from variety of sources: natural crystals from Ural Mountains and synthetic grown by flux method in Russia. Natural colourless and blue topaz from
Ukraine was investigated. The sample thickness was in the range of $0.1-2.15 \mathrm{~mm}$.

The neutron irradiation was performed at the Latvian $5 \mathrm{MW}$ water-water research reactor. The fluence of fast neutrons with energy $>0.11 \mathrm{MeV}$ was in the range $10^{14}-5 \cdot 10^{18} \mathrm{~cm}^{-2}$. A cadmium filter was used for absorption of thermal neutrons. Irradiation by electrons with energy of $3.5 \mathrm{MeV}$ of integral fluence up to $10^{16} \mathrm{~cm}^{-2}$ was carried out in accelerator ELU (Salaspils, Latvia). The sample temperature did not exceed $60^{\circ} \mathrm{C}$ during the electron irradiation and was below $40^{\circ} \mathrm{C}$ during the neutron irradiation.

The luminescence studies were carried out using two setups for spectral measurements. The first setup was equipped with a SPM-2 monochromator having diffraction grating of 651 lines per $\mathrm{mm}$. The crystals were excited with a high pressure xenon lamp (DKSEL-1000) $1000 \mathrm{~W}$ connected to the monochromator SPM-1(Carl Zeiss Iena) with a quartz prism. Signal detection was carried out with a photomultiplier tube (FEU-119) by a synchronic detection method. The second setup was equipped with a deuterium lamp LDD-400 as a source of UV light and a grating monochromator MDR-2 in the excitation channel. In the case of PL measurements the luminescence signal was analyzed by Shamrock monochromator SR-303i-B using a grating with 150 lines/mm and $500 \mathrm{~nm}$ blaze and detected with a CCD camera DV420A-BU2 in the accumulation mode. The standard technique to measure absorption spectra has been based on a "Specord M-40" two-beam spectrometer operating in the $200-900 \mathrm{~nm}$ regions and "Specord 210" (Analytikjena) double-beam spectrophotometer operating in the spectral region of 190-1100 nm. Optical measurements before and after irradiation were carried out in the temperature range 8-300 K. 


\section{RESULTS AND DISCUSSION}

\section{A. Topaz crystals}

Topaz is an aluminium fluorosilicate with a fairly constant chemical composition $\mathrm{Al}_{2} \mathrm{SiO}_{4}(\mathrm{OH}, \mathrm{F})_{2}$. The only major variation found in different samples is related to the $[\mathrm{OH}] /[\mathrm{F}]$ concentration ratio. The structure of topaz consists of $\mathrm{SiO}_{4}$ groups linking octahedral chains of $\mathrm{Al}\left[\mathrm{O}_{4}(\mathrm{~F}, \mathrm{OH})_{2}\right]$ in a zigzag fashion parallel to the crystalline c-axis. Four of six anions surrounding $\mathrm{Al}^{3+}$ ion belong to $\mathrm{SiO}_{4}$ tetrahedron and the remaining two anions are $\mathrm{F}^{-}$or $\mathrm{OH}^{-}$group. Topaz crystallizes in the orthorhombic system, space group Pbnm [7], [8] and is normally found as well-developed prismatic crystals with pyramidal terminations

Natural topaz stone has the structure of an aluminum silicate fluoride hydroxide $\mathrm{Al}_{2}\left[\mathrm{SiO}_{4}\right](\mathrm{F}$, $\mathrm{OH})_{2}$, and is usually colorless or has an unattractive color. Figure 1. gives the absorption spectra of topaz single crystals before irradiation (curve 1), after fast neutron irradiation (curve 2) and natural blue topaz from Volodarsk Volynskii, Ukraine (curve 3). Before irradiation some zero-phonon lines were observed in the region of the $\mathrm{Cr}^{3+}$ ion electron transition ${ }^{4} \mathrm{~A}_{2 \mathrm{~g}} \rightarrow{ }^{2} \mathrm{E}_{\mathrm{g}}$ in topaz spectra (Fig. 2). After irradiation in absorption spectra there appears an intense absorption at $230 \mathrm{~nm}$ and occur the characteristic maxima at 305 , 410, 446, $590 \mathrm{~nm}$. Two lines around 230 and $305 \mathrm{~nm}$ belong to a single defect such as silanone $(=\mathrm{Si}=\mathrm{O})$ as it was suggested in [9] basing on similar lines observed in spodumene. Blue color is connected with a broad absorption band in the red part of the spectrum generated by the so-colled R-centers (two F-vacancies with two trapped electrons) [10]. It was previously concluded that the optical absorption band centered at $620 \mathrm{~nm}$ is closely correlated with an $\mathrm{O}^{-}$center interacting with two $\mathrm{Al}$ ions of the topaz structure. This $\mathrm{O}^{-}$center is produced by the irradiation in the hydroxyl sites which substitutes for fluorine in the topaz structure [11], [12]. As suggested Priest V. at al [13] the blue defects in neutron damaged topaz is the doubly occupied dangling silicon bond. We assume that the band $\sim 620 \mathrm{~nm}$ includes not only the above mentioned bands, but also the bands associated with the presence of impurities of $\mathrm{Cr}^{3+}, \mathrm{Fe}^{2+}$ and $\mathrm{Mn}^{2+}$ ions. The calculations performed in [14] using $\mathrm{AlCrFH}_{7} \mathrm{O}_{11} \mathrm{Si}$ model molecule with unrestricted CIS method to simulate UV and visible spectra shows that the theoretical spectrum of the model is in a considerably good agreement with experimental one.

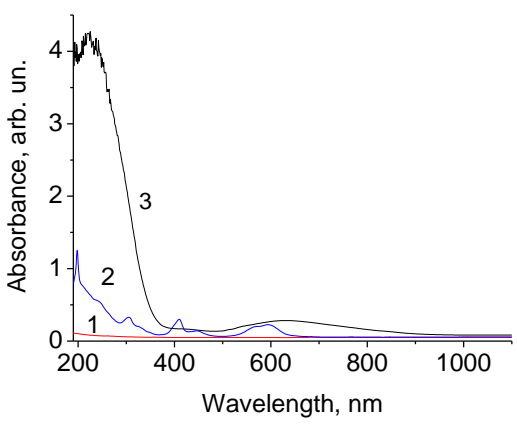

Fig.1. Topaz absorption spectra before (1) and after neutron irradiation (2), (3) natural blue topaz from Volodarsk Volynskii,

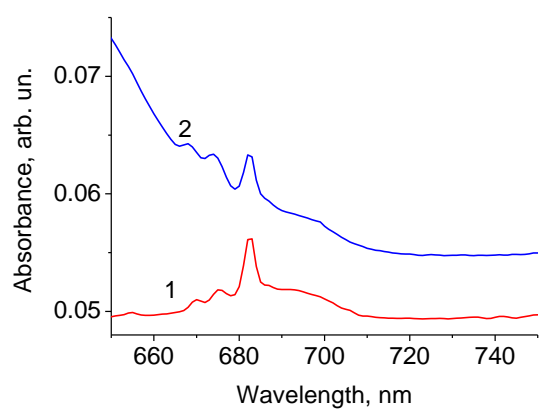

Ukraine.

Fig. 2. Topaz absorption spectra before (1) and after neutron irradiation (2)

Photoluminescence spectra in natural colourless topaz excitated at $\lambda_{\text {exc }}=251 \mathrm{~nm}$ and $\lambda_{\text {exc }}=447 \mathrm{~nm}$ registered at $300 \mathrm{~K}$ are shown in Fig. 3. In photoluminescence spectra of topaz crystal exited at $251 \mathrm{~nm}$, it is possible to separate an intensive band $350 \mathrm{~nm}$ with shoulder about $364 \mathrm{~nm}$, and less expressed $390 \mathrm{~nm}, 420 \mathrm{~nm}$ and $464 \mathrm{~nm}$ bands. Upon excitation $447 \mathrm{~nm}$ it is observed two wide bands at maxima at 575 and $800 \mathrm{~nm}$.

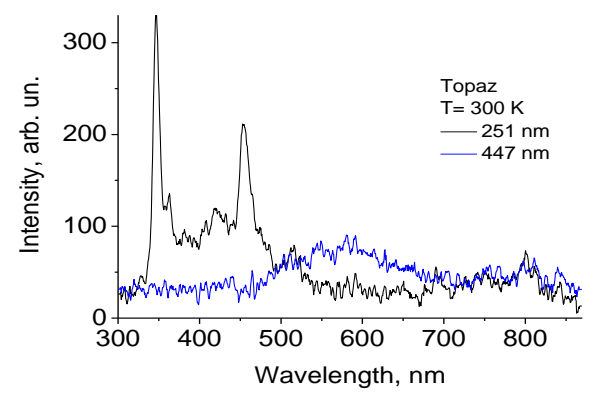

Fig.3. Photoluminescence spectra of topaz crystal at 230 and 447 $\mathrm{nm}$ excitation wavelengths.

Luminescence at $390 \mathrm{~nm}$ belongs to own $\left[\mathrm{SiO}_{4}\right]^{3+}$ hole centers. The emission band with maxima $464 \mathrm{~nm}$ is connected with $\left[\mathrm{AlO}_{4}\right]^{4-}$ center arising from isomorphic substitution of silicon by aluminum in the silicon-oxygen tetrahedron. Wide luminescence bands 
at excitation wavelength $447 \mathrm{~nm}$ may be connected with presence of $\mathrm{Mn}^{2+}(\sim 600 \mathrm{~nm})$ and $\mathrm{Fe}^{3+}(\sim 800 \mathrm{~nm})$ isomorphically substituting for $\mathrm{Si}^{4+}$ in the siliconoxygen tetrahedron.

\section{B. Beryl crystal}

Beryl $\left(\mathrm{Be}_{3} \mathrm{Al}_{2} \mathrm{Si}_{6} \mathrm{O}_{18}\right)$ is a silicate mineral belonging to the cyclosilicate class. It has a honeycomb-like hexagonal structure and belongs to the $\mathrm{P} 6 / \mathrm{mcc}$ space group. The axial parameters are $\mathrm{c}=9.17^{\circ} \mathrm{A}$ and $\mathrm{a}=9.21$ ${ }^{\circ} \mathrm{A}[15,16]$. Each ion of $\mathrm{Al}$ is surrounded by 6 oxygen atoms located in the vertices of almost regular octahedron. Each octahedral complex $\mathrm{AlO}_{6}$ is linked to six $\mathrm{SiO}_{4}$ tetrahedron through common oxygen atoms. The disposition of the octahedral is such that allows the formation of $\mathrm{Si}_{6} \mathrm{O}_{18}$ rings. Each beryllium is surrounded by 4 oxygens forming distorted tetrahedron. The $\mathrm{Si}_{6} \mathrm{O}_{18}$ rings lay one above the other along the C6 axis forming intercommunicating channels of quite large dimensions. The oxygen that is shared among $\mathrm{Si}^{4+}$ ions is an $\mathrm{O} 1$ type oxygen and the oxygen that is linked to $\mathrm{Al}^{3+}$ and $\mathrm{Be}^{2+}$ ions is an $\mathrm{O} 2$ type oxygen. Taking into account this configuration, each $\mathrm{Si}^{4+}$ ion is surrounded by two $\mathrm{O} 1$ oxygens and two $\mathrm{O} 2$ oxygens. The diameter of the channels varies from a minimum of $2.8^{\circ} \mathrm{A}$ in the plane of the $\mathrm{Si}_{6} \mathrm{O}_{18}$ ring and a maximum of $5.1 \mathrm{~A}^{\circ}$, midway between two neighboring rings. Because of this structure, impurities can be substitutional, interstitial and also located in the channels.

The color of beryl $\mathrm{Be}_{3} \mathrm{Al}_{2} \mathrm{Si}_{6} \mathrm{O}_{18}$ is usually determined by its $\mathrm{Fe}^{2+}$ and $\mathrm{Fe}^{3+}$ content. $\mathrm{Fe}^{2+}$ produces pale blue color, $\mathrm{Fe}^{3+}$ produces golden-yellow color, and when both $\mathrm{Fe}^{2+}$ and $\mathrm{Fe}^{3+}$ are present, the color is dark blue. Green color in iron-containing beryl usually results from a mixture of blue and yellow components. Green color can also come from $\mathrm{Cr}^{3+}$ as it is found in various emeralds. Beryl is naturally transparent, however inclusions and impurities may make it opaque.

Absorption spectra for three beryl crystals are shown in Fig. 4. Beryl, when containing sufficient chromium (about $0.1 \%$ or more) is characterized by two broad bands near 430 and $600 \mathrm{~nm}$ (Fig. 4, curve 1), as well sharp R-lines (Fig 5.)

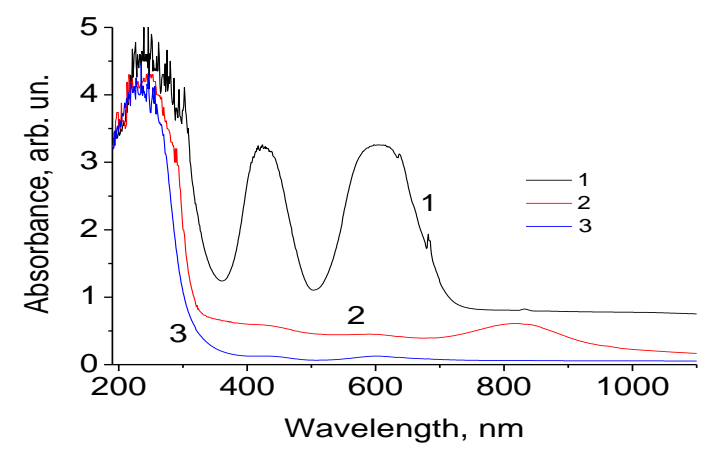

Fig.4. Absorption spectra of beryl crystals: 1. synthetic beryl containing Cr $0.1 \%$ chromium impurity, 2. natural beryl from Ural, 3. synthetic flux beryl.

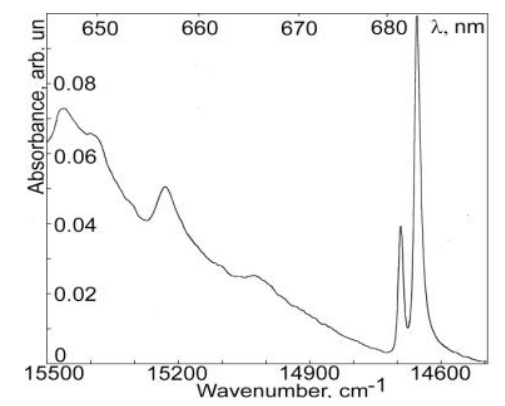

Fig. 5. Absorption spectra of beryl containing $0.1 \% \mathrm{Cr}$ :

The observed absorption bands associated with electronic transitions of chromium ion: $630 \mathrm{~nm}$ transition ${ }^{4} \mathrm{~A}_{2 \mathrm{~g}}(\mathrm{~F}) \rightarrow{ }^{4} \mathrm{~T}_{2 \mathrm{~g}}(\mathrm{~F})$ and $431 \mathrm{~nm}$ transition ${ }^{4} \mathrm{~A}_{2 \mathrm{~g}}(\mathrm{~F}) \rightarrow{ }^{4} \mathrm{~T}_{1 \mathrm{~g}}(\mathrm{~F})$ [17]. The wide absorption band with peak in the near-infrared range at $813 \mathrm{~nm}$ is observed in natural beryl spectra. The band is generally ascribed to internal electron transition of ${ }^{5} \mathrm{~T}_{2}\left({ }^{5} \mathrm{D}\right) \rightarrow{ }^{5} \mathrm{E}\left({ }^{5} \mathrm{D}\right)$ of $\mathrm{Fe}_{\mathrm{VI}}{ }^{2+}$ ions localized in octahedral aluminum sites of beryl $[18,19]$. Absorption spectra of beryl containing chromium before and after neutron irradiation are given in Fig.6.

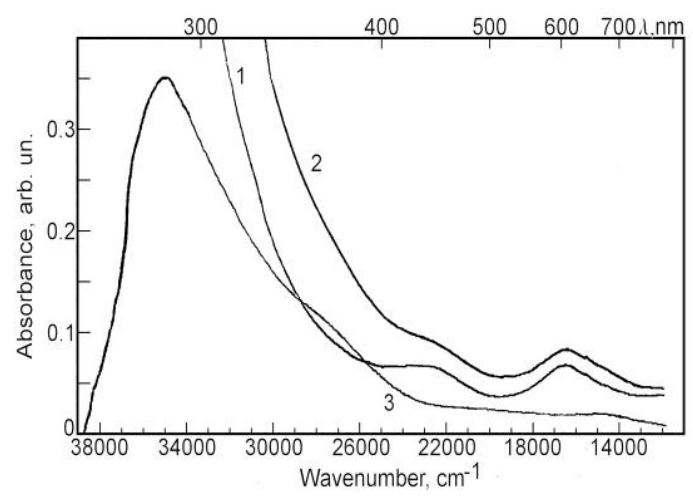

Fig. 6. Absorption spectra of beryl:Cr: 1. before irradiation, 2. after fast neutron irradiation $\Phi=10^{16} \mathrm{~cm}^{-2}$, 3.additional absorption spectrum.

Fast neutron irradiation produces additional bands with maxima: 286, 370, 500 and $667 \mathrm{~nm}$. Most probably these bands are due to anion intrinsic defects (the $\mathrm{F}^{+}, \mathrm{F}, \mathrm{F}_{2}, \mathrm{~F}_{2}^{+}$and $\mathrm{F}_{2}^{+}$centers) similar to observed in $\mathrm{Al}_{2} \mathrm{O}_{3}$ [20], [21]. Natural pale blue beryl crystals contain iron ions and small amount of chromium ions. Prior to irradiation there were not observed absorption bands associated with electronic transitions ${ }^{4} \mathrm{~A}_{2 \mathrm{~g}}(\mathrm{~F}) \rightarrow$ ${ }^{4} \mathrm{~T}_{2 \mathrm{~g}}(\mathrm{~F})(630 \mathrm{~nm})$ and ${ }^{4} \mathrm{~A}_{2 \mathrm{~g}}(\mathrm{~F}) \rightarrow{ }^{4} \mathrm{~T}_{1 \mathrm{~g}}(\mathrm{~F})(431 \mathrm{~nm})$ of chromium ions. Absorption spectra contain only band $813 \mathrm{~nm}$ associated with $\mathrm{Fe}^{2+}$ ions. After the impact of fast neutron fluence of $10^{13}-10^{17} \mathrm{~cm}^{-2}$ the intensity of $813 \mathrm{~nm}$ band reduced and the absorption edge shifted due to appearance of an intense absorption band in the UV region. Besides, after irradiation there appears the additional band with maximum $690 \mathrm{~nm}$ (Fig. 7). The crystal color is changed from pale blue to light green. 


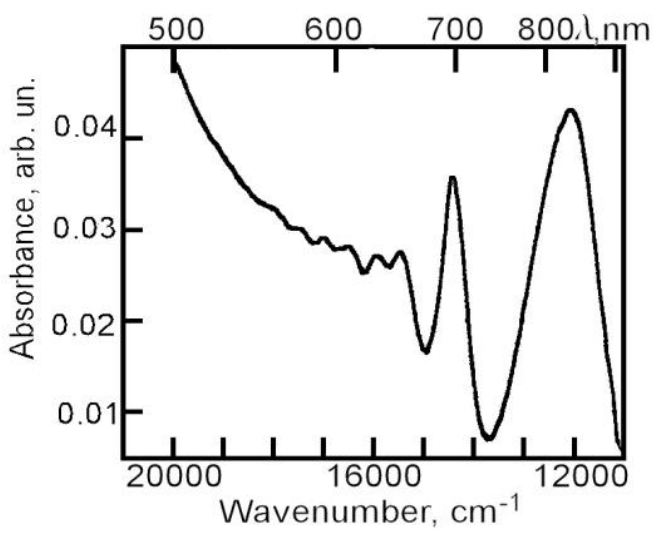

Fig.7. Absorption spectra of natural pale blue beryl after fast neutron irradiation $\Phi=10^{16} \mathrm{~cm}^{-2}$.

Dependence of intensity of $813 \mathrm{~nm}(1)$ and $694 \mathrm{~nm}$ (2) absorption bands on fast neutron fluence in pale blue beryl is shown in Figure 8 .

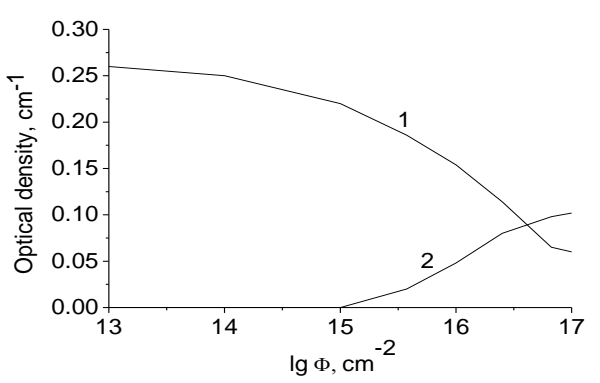

Fig. 8. Pale blue beryl absorption band $813 \mathrm{~nm}$ (1) and $694 \mathrm{~nm}$ (2) intensities as functions of fast neutron fluence.

As previously reported [22]-[24] irradiation produces radicals $\mathrm{NO}_{3}{ }^{0}$ and $\mathrm{CO}_{3}{ }^{-}$, which are called Maxixe and Maxixe-type color centers and which seem to be related to blue colors in beryl. We suppose that the band with maxima $690 \mathrm{~nm}$ belongs to complex center which consists from $\mathrm{Cr}^{3+}$ ions and radiation defects ( $\mathrm{F}$ or $\mathrm{F}^{+}$- center). Concentration of $\mathrm{F}$ and $\mathrm{F}^{+}$centers are increasing with neutron fluence increasing. The number of perturbed chromium sites also increased and the band became more intense. The containing chromium impurity ions may be the chromium ions in the lower valence, such as bivalent $\mathrm{Cr}^{2+}$ impurity ions. The $\mathrm{Cr}^{2+}$ impurity ions are oxidized into $\mathrm{Cr}^{3+}$. $\mathrm{A} \mathrm{Cr}^{3+}$ impurity ion has the same valence as the substituted $\mathrm{Al}^{3+}$ ion. Possible processes for chromium valence change are:

$$
\text { 1. } \mathrm{Cr}^{2+} \rightarrow \mathrm{Cr}^{3+}+\mathrm{e}^{+} ; 2 . \mathrm{Cr}^{2+}+\mathrm{V} \rightarrow \mathrm{Cr}^{3+}+\mathrm{X}_{\mathrm{s}}^{-}
$$

$\left(\mathrm{X}_{\mathrm{s}}^{-}\right.$-the constituent anions or radical in normal lattice of beryl crystal [25]). Therefore, the newly produced $\mathrm{Cr}^{3+}$ impurity ions prefer to lie in the octahedral sites in order to maintain the local charge neutrality of the crystal.

The photoluminescence spectra of flux beryl at $\lambda_{\mathrm{ex}}=$ $271 \mathrm{~nm}$ and different temperature are given in Fig. 9. Wide band at $740 \mathrm{~nm}$ observed at $\mathrm{T}=300 \mathrm{~K}$ is connected with $\mathrm{Fe}^{2+}$ ions. Narrow lines in region from 680 to $720 \mathrm{~nm}$ at $\mathrm{T}=8 \mathrm{~K}$ belong to single $\mathrm{Cr}^{3+}(\mathrm{R}-$ lines) and $\mathrm{Cr}^{3+}$ - pairs (N- lines). The photoluminescence band at $525 \mathrm{~nm}$ intensity increases with temperature decrease.

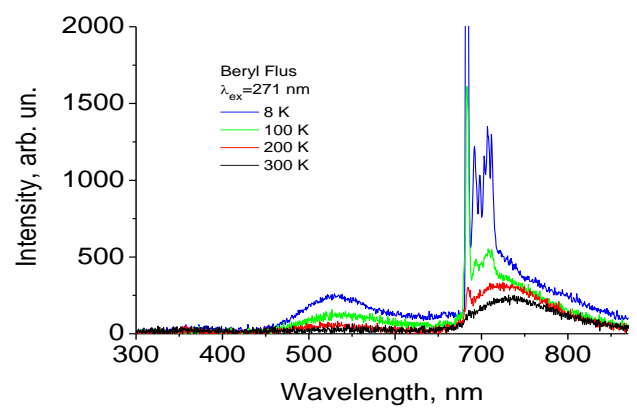

Fig. 9. Photoluminescence spectra of beryl crystal at different temperature, excitation wavelengths $271 \mathrm{~nm}$.

\section{Yttrium aluminum garnet}

The cubic cell of garnet compound $\mathrm{A}_{3} \mathrm{~B}_{2}{ }_{2} \mathrm{~B}^{\prime}{ }_{3} \mathrm{O}_{12}$ contains eight formula units, where A, B', B" are metal ions occupying sites of different symmetry [26]. The crystal structure of $\mathrm{Y}_{3} \mathrm{Al}_{5} \mathrm{O}_{12}$ (YAG) has a bcc structure (space group Ia3d or $\mathrm{O}^{10}{ }_{\mathrm{h}}$ ) with 160 atoms in the cubic (primitive) cell. Y ions (A atoms) occupy 24 (c) sites and each of them is dodecahedrally coordinated to eight oxygen ions. Oxygen atoms occupy 96 (h) sites whose exact location depends on three structural parameters - $\mathrm{x}, \mathrm{y}$, and $\mathrm{z}$ and are different for different garnet oxides. There are two different sites for $\mathrm{Al}$ : $\mathrm{Al}_{\text {oct }}$ (B' atoms) occupy 16 (a) sites with octahedral point symmetry $\left(\mathrm{C}_{3 \mathrm{i}}\right)$; and $\mathrm{Al}_{\text {tet }}$ (B") atoms occupy 24 (d) sites with tetrahedral point symmetry $\left(\mathrm{S}_{4}\right)$. The garnet structure may be considered as interconnected octahedrons, tetrahedrons, and dodecahedrons with shared oxygen atoms at the corners [26]. Each oxygen ion is a member of two dodecahedrons, one octahedron, and one tetrahedron. $\mathrm{Y}^{3+}$ and $\mathrm{Al}^{3+}$ in YAG can be replaced by many kinds of other cations with different valence and size within a suitable range.

The optical absorption spectra of four garnet single crystals measured at room temperature before irradiation are similar. Figure 10. gives the absorption spectra of yttrium aluminum garnet single crystals (curve 1) before irradiation, after fast neutron irradiation (curve 2) and after electron irradiation (curve 3). Before irradiation there are observed bands at 370,500 and $830 \mathrm{~nm}$. After neutron irradiation additional bands with maxima 549.5, 595.2 and 714.3 $\mathrm{nm}$ appear in absorption spectra of YAG containing manganese impurities. The 370 and $500 \mathrm{~nm}$ bands intensity increases but the $830 \mathrm{~nm}$ band intensity decreases after fast neutron irradiation. A weak band $370 \mathrm{~nm}$ corresponds to F-type centers [27].

Broad orange luminescence band in the range 580$620 \mathrm{~nm}$ appears at room temperature (Fig. 11, curve 1). Luminescence spectrum of $\mathrm{Y}_{3} \mathrm{Al}_{5-\mathrm{x}} \mathrm{Mn}_{\mathrm{x}} \mathrm{O}_{12}$ single crystal measured at liquid nitrogen temperature contains the following main features: a sharp line at 
$587 \mathrm{~nm}$ and a series of weaker lines on the long wavelength side of the sharp lines (curve 2, Fig.11).

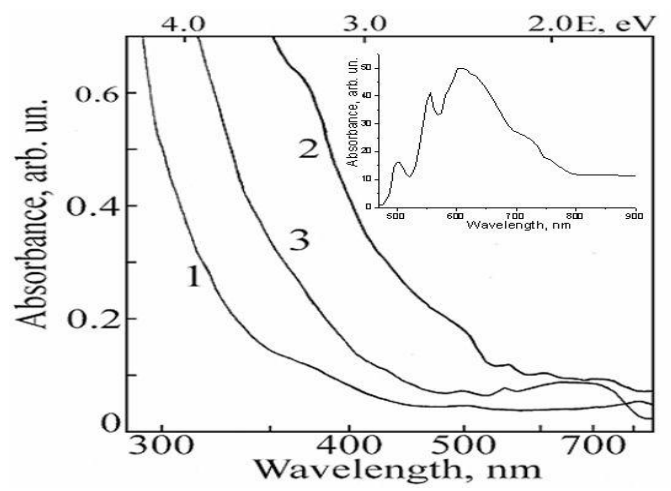

Fig. 10. Absorption spectra of $\mathrm{Y}_{3} \mathrm{Al}_{5 \mathrm{x}} \mathrm{Mn}_{\mathrm{x}} \mathrm{O}_{12}$ : 1. before irradiation, 2. after neutron irradiation $\Phi=10^{16} \mathrm{~cm}^{-2}$, 3.after electron irradiation $\Phi=10^{16} \mathrm{~cm}^{-2}$. In the inset: additional absorption spectrum of neutron irradiated $\mathrm{Y}_{3} \mathrm{Al}_{4.963} \mathrm{Mn}_{0.037} \mathrm{O}_{12}$ crystal.

After irradiation with fast neutrons at fluence $6 \cdot 10^{18} \mathrm{~cm}^{-2}$ the photoluminescence spectrum at liquid nitrogen temperature consists of a broad structureless band with a maximum at $607 \mathrm{~nm}$ (Fig. 11, inset). A little sharp line is seen also as a shoulder of the main band. Neutron irradiation causes production of anion and cation vacancies in the crystal. F-centre absorption band at $370 \mathrm{~nm}$ arises. After PL and optical measurement thermal annealing of the $\mathrm{Y}_{3} \mathrm{Al}_{4.988} \mathrm{Mn}_{0.012} \mathrm{O}_{12}$ and $\mathrm{Y}_{3} \mathrm{Al}_{4.975} \mathrm{Mn}_{0.025} \mathrm{O}_{12}$ crystals has been carried out. The crystals were heated in air at $473 \mathrm{~K}$ during 2 hours. The PL spectra measured after annealing at liquid nitrogen temperature are similar to the PL spectra before irradiation.

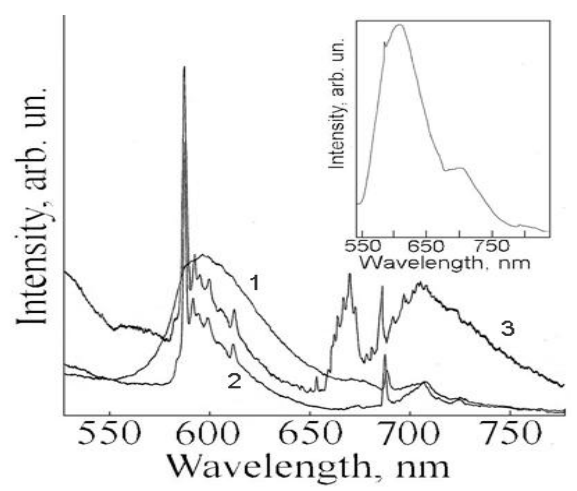

Fig. 11. Photoluminescence spectra of Y3Al5-xMnxO12 at $\lambda \mathrm{ex}=470 \mathrm{~nm}: 1$. at room temperature, 2. at $80 \mathrm{~K}$, and 3 . after electron irradiation. The inset shows photoluminescence spectrum of a neutron- irradiated crystal.

It is suggested, that the reversibility of broadening of luminescence lines of $\mathrm{Mn} 2+$ ions is the evidence of the structure ordering reconstruction after annealing. The relatively low annealing temperature shows, that the structure changes after neutron irradiation concern only cation sublattice. Photoluminescence spectra of Y3Al4.988Mn0.012O12 carried out at liquid nitrogen temperature after electron irradiation have discovered a series of relatively narrow lines in 645-680 nm spectral regions. Mn2+ ions have a $3 \mathrm{~d} 5$ electron configuration. All electron transitions for this configuration are forbidden by the selection rules of spin and parity. The restrictions caused by the selection rule are removed owing to the exchange interaction. The emission with maxima around $590 \mathrm{~nm}$ is attributed to the $4 \mathrm{~T} 1 \mathrm{~g} \rightarrow 6 \mathrm{~A} 1 \mathrm{~g}$ transition of $\mathrm{Mn} 2+$ ions in octahedral sites. Luminescence spectrum of $\mathrm{Mn} 4+(3 \mathrm{~d} 3)$, which is isoelectronic to $\mathrm{Cr} 3+$ consists of the sharp R lines peaked around 645-675 nm, which are caused mainly by the $2 \mathrm{Eg} \rightarrow 4 \mathrm{~A} 2 \mathrm{~g}$ transitions and partly by the $4 \mathrm{~T} 2 \mathrm{~g} \rightarrow 4 \mathrm{~A} 2 \mathrm{~g}$ transitions. These bands are observed after electron irradiation of Y3Al5xMnxO12 together with the Mn2+ ion luminescence in octahedral sites. In contrast to paper [5] the green luminescence was not observed in our single crystals. The broad band emission of $\mathrm{Cr} 3+$ with a maximum at $695 \mathrm{~nm}$ is ascribed to the $4 \mathrm{~T} 2 \mathrm{~g} \rightarrow 4 \mathrm{~A} 2 \mathrm{~g}$ transition, the sharp and narrow bands at $685 \mathrm{~nm}$ are due to $2 \mathrm{Eg} \rightarrow$ $4 \mathrm{~A} 2 \mathrm{~g}$. The diffused band centered at $675 \mathrm{~nm}$ (antiStokes vibronic sidebands) and two sharp diffused bands at 710 and $725 \mathrm{~nm}$ corresponding to the vibronic sidebands are observed in all investigated YAG crystals before and after irradiation (Fig.10). Hodges et al. [28] pointed out that $\mathrm{Mn} 2+$ in yttrium aluminum garnet can enter into any of three kinds of sites which are located in the center of dodecahedron, octahedron and tetrahedron, respectively [29, 30]. The presence of a nearby $\mathrm{F}$ or $\mathrm{F}+$ center can modify the neighborhood the $\mathrm{Mn} 2+$ impurity site to produce an effective increase in the crystal field. In addition to the shift in energy, the perturbation induced by the $\mathrm{F}$ or $\mathrm{F}+$ center can increase the oscillator strength by introducing odd components to the crystal field, or by exchange coupling between the $\mathrm{F}$ or $\mathrm{F}+$ center and the $\mathrm{Mn} 2+$ impurity. The enhancement of the oscillator strength by the exchange interaction has been previously observed between $\mathrm{F}$ centers and transition metal impurity ions in $\mathrm{MgF} 2, \mathrm{MgAl} 2 \mathrm{O} 4$ and $\mathrm{MgO}$ $[31,32]$. As the concentration of $\mathrm{F}$ and $\mathrm{F}+$ centers increased, the number of perturbed manganese sites also increased, so that the excitation peaks became more intense as a function of neutron dose. It is possible to assume that the band broadening is connected with a complex center "Mn2+-F+ (or F centre)". A part of holes generated after irradiation are trapped by $\mathrm{Mn} 2+$, which then produces $\mathrm{Mn} 3+$ and Mn4+ ions.

\section{CONCLUSIONS}

The absorption and luminescence spectra behaviour of natural (topaz, beryl) and synthetic (beryl, yttrium aluminum garnet) minerals containing transition metal ions exposed to a fluence of fast neutrons up to $10^{18} \mathrm{~cm}^{-2}(\mathrm{E}>0.1 \mathrm{MeV})$ and electron are investigated.

We assume that the band $\sim 620 \mathrm{~nm}$ in topaz crystals is associated with the presence of impurities of $\mathrm{Cr}^{3+}$, $\mathrm{Fe}^{2+}$ and $\mathrm{Mn}^{2+}$ ions. Band with maxima $690 \mathrm{~nm}$ in beryl crystal belongs to complex center which consists from $\mathrm{Cr}^{3+}$ ions and radiation defects ( $\mathrm{F}$ or $\mathrm{F}^{+}$- center). Band broadening in aluminium yttrium garnet is connected with a complex center " $\mathrm{Mn}^{2+-} \mathrm{F}^{+}$(or $\mathrm{F}$ centre)". Electron irradiation produced broad band with a complex structure related to $\mathrm{Mn}^{4+}$ ions. 
Exchange interaction between radiation defect and impurity ions during neutron irradiation and electron irradiation leads to appearance of additional absorption and luminescence bands and bands broadening in investigated crystals.

\section{$\mathrm{V}$ ACKNOWLEDGMENTS}

This work was supported by the grant of the Latvian Government (No 402/2012).

\section{REFERENCES}

[1] C. M. S. Magalhaes, Z. S. Macedo, M. E. S. Valerio, A. S. Hermandes, and D. N. Souza, "Preparation of compozites of topaz embedded in glass matrix for applications in solids state thermoluminescence dosimetry". Nuclear Instruments and Methods in Physics Research B, vol. 218. pp. 277-282, 2004.

[2] D. N. Souza, M. E. S. Valerio, J. F. Lima, "Dosimetric properties of natural Brazilian topaz: A thermally stimulated exoeletronic emission and thermoluminescence study". Nuclear Instruments and Methods in Physics Research B, vol. 166-167, pp. 209-214, 2000

[3] K. S. Bomfim and D. N. Souza, Topaz Composites to Electron Dosimetry. International Nuclear Atlantic Conference - INAC 2007, Santos SP, Brazil, September 30- October 5, 2007, 4 p.

[4] N. Ter-Gabrielyan, L. D. Merkle, E. R. Kupp, G. L. Messing and M. Dubinskii, "Efficient resonantly pumped tape cast composite ceramic Er:YAG laser at 1645 nm”, Opt. Lett., vol. 35, Iss. 7, pp. 922-924, 2010.

[5] V. Singh, R. P. S. Chakradhar, J. L.,Rao and H. Y. Kwak, "Green luminescence and EPR studies on Mn-activated yttrium aluminum garnet phosphor", J. Appl. Phys.B, vol. 98, No 2-3, pp. 407-415, 2010.

[6] B. Henderson, "Color, symmetry and imperfect crystals", Contemporary Physics, vol. 19, Issue 3, pp. 225-267, 1978.

[7] P. H. Ribbe, G. V. Gibbs, "The crystal structure of topaz and its relation to physical properties", Am. Mineral., vol. 56, pp.24 30, 1971.

[8] P. A. Northrup, R. Leinenweber, J. B. Parise, "The location of $\mathrm{H}$ in the high-pressure synthetic $\mathrm{Al}_{2} \mathrm{SiO}_{4}(\mathrm{OH})_{2}$ ". Am. Mineral., vol. 79, pp.401-404, 1994.

[9] W. Bonventi Jr, S. Isotani, and A. R. Pereira Albuquerque, "Color Dependence on Thickness in Topaz Crystal from Brazil”. Advances in Condensed Matter Physics Article ID 873804. 2012, 8 pages doi:10.1155/2012

[10] A. N. Platonov, M. N. Taran and V. S. Balyatskii, Nature of color gems, Moscow: Nedra, 1984 (in Russian).

[11]D. N. Da Silva, K. J. Guedes, M. V. B. Pinheiro, J.-M. Spaeth, K. Krambrock, "The microscopic structure of the oxygenaluminum hole center in natural and neutron irradiated blue topaz", Phys. Chem. Min., vol. 32, pp. 436-441, 2005.

[12] A. S. Leal, K. Krambrock, L. G. M. Ribeiro, M. A. B. C. Menezes, P. Vermaercke, L. Sneyers, "Study of neutron irradiation-induced colors in Brazilian topaz". Nuclear Instruments and Methods in Physics Research A, vol. 580, pp. 423-426, 2007.
[13] V. Priest, D. L. Cowan, D.G. Reichel and F. K. Ross, "A dangling-silicon-bond defect in topaz". J. Applied Physics, vol. 68, pp. 3030-3037, 1990.

[14]H. Goto, A. Niwa, D. C. Greenhidge, N. Kato, T. Ida, M. Mizuno, K. Endo, T. Tada, "Analysis of UV-Visible Absorption Spectra foe Quartz and Topaz in Silicate Minerals by MO Calculation Using the Claster Model Molecules". J. of Surface Analysis, vol. 12, pp.249-253, 2005.

[15]D. L. Wood and K. Nassau," The characterization of beryl and emerald by visible and infrared absorption spectroscopy". Amer. Mineral., vol. 53, pp.777-800, 1868

[16]W. A. Deer, R. A. Howie and I. Zussman, An Introduction to the Rock-Forming Minerals, 2, London: Longman Group Ltd, 1978.

[17] Minerals: A Handbook, Ed. By Chukhrov F. V., Moscow: Nauka, 1981 (in Russian.)

[18]A. I. Bakhtin, Rock-Forming Silicates: Optical Spectra, Crystal Chemistry, Coloration Typomorphism, Kazan: Kazan State University Press, 1985 (in Russian)

[19]A. S. Marfunin, Spectroscopy, Luminescence and Radiation Centres in Minerals, Berlin: Springer, 1979.

[20]K. Atobe, N. Nishimoto, M. Nakagawa, "Irradiation-Induced Aggregate Centers in single crystals $\mathrm{Al}_{2} \mathrm{O}_{3}$ ". Phys. Stat. Sol. (a), vol. 89 , pp. $155-162,1985$

[21] K. H. Lee and J. H. Crawford Jr, "Electron centers in singlecrystal $\mathrm{Al}_{2} \mathrm{O}_{3}$. Phys. Rev., vol. 15, pp. 4065-4070, 1977.

[22] K. Nassau, B. E. Prescott, D. L. Wood, "The deep blue Maxixetype color center in beryl”. Am. Mineral., vol. 61, pp. 100-107, 1976.

[23]L. O. Anderson, "The difference between Maxixe beryl and Maxixe-type beryl: an electron paramagnetic resonance investigation". J. Gemmology, vol. 16, pp.313-317, 1979.

[24]A. Edgar and E. R.Vance, "Electron paramagnetic resonance, optical absorption, and magnetic circular dichroism studies of the $\mathrm{CO}_{3}$ molecular-ion in irradiated natural beryl". Phys. Chem. Mineral. vol.1, pp. 165-168, 1977

[25]W. Chen, H. Gu, J. Liu, F. Wang, D. Ma, R. Zhu, "Electrolytic coloration and spectral properties of natural beryl crystal". Physica B, vol. 405, pp 331- 334, 2010.

[26]F. S. Galasso, Structure and Properties of Inorganic Solids, New-York: Pergamon, 1970

[27]K Chakrabarti, "Photobleaching and photoluminescence in neutron-irradiated YAG”. J Phys. Chem. Solids, vol. 49, pp.1009-1011, 1988.

[28]J. A. Hodges, "Temperature dependent EPR measurements of $\mathrm{Mn}^{2+}$ in diamagnetic garnets". J. Phys. Chem. Solids, vol. 35, N 4-5, pp. 1385-1392, 1974

[29]P. Gavrilovic and Sh. Singh, "Tunable solid state crystalline laser material" U. S. Patent 5,280,534, Jan. 18, 1994.

[30]A. Nijs, M. M. Verweij, G. A. Blasse, "Divalent manganese Garnet with Red luminescence". Mater.Chem. Phys., vol. 30, pp. 199-203, 1992.

[31]M. Okada, T. Kawakubo, T. Seiyama, M. Nakagawa, "Enhancement of 3d-Electron Transition in Neutron irradiated MgO:Mn ${ }^{2+}$ Crystals". Phys. Stat. sol. (b), vol. 144, pp.903-909, 1987.

[32] N. Mironova and U. Ulmanis, Radiation defect and iron group metal ions in oxides, Riga:Zinatne, 1988 (in Russian). 